\title{
ON THE CORROSION OF TWO TYPES OF BRONZES UNDER CAVITATION
}

\author{
Cristian Ștefan DUMITRIU \\ Transilvania University of Brasov, Romania \\ e-mail: cristian.dumitriu@unitbv.ro
}

\begin{abstract}
This article contains the results of the experiments concerning the mass loss of two types of bronze in seawater in the cavitation produced by ultrasound generated by a high-frequency generator. The mass loss models are presented for the experimental conditions when the generator worked at different powers - $80 \mathrm{~W}, 120$ $W$, and $180 \mathrm{~W}$. In all scenarios, the results show that the bronze with Sn has the highest mass loss in the cavitation field.
\end{abstract}

KEYWORDS: cavitation, bronze, mass loss, gravimetric index

\section{Introduction}

The phenomena related to the mechanical erosion of materials in the cavitation field are of major importance for selecting the alloys used in the naval industry. Some are copper alloys employed for building propellers, bilge systems, ballast installation, and other connection pieces that work in cavitation conditions. Due to the necessity of materials with high resistance to corrosion in this industry, different authors analysed the behavior of some copper alloys in seawater [1-3], while only a few investigated their behavior under cavitation and studied the corrosion type [4-5]. Ivanov [6] showed that some bronzes with Sn have gravimetric index $0.004-0.015 \mathrm{~g} / \mathrm{m}^{2} \mathrm{~h}^{-1}$ at a concentration of $0.19 \%$ (at $15{ }^{\circ} \mathrm{C}$ ) and have high corrosion resistance in seawater vapors at high pressure. The same study [6] emphasized that the resistance of bronzes with $\mathrm{Al}$ and $\mathrm{Ni}$ can be nine times bigger than that of the bronzes with $\mathrm{Sn}$, depending on the percentages of $\mathrm{Al}$ and Ni. Adding $\mathrm{Ni}$ in a bronze containing $\mathrm{Al}$ and $\mathrm{Fe}$ increases its mechanical resistance, resistance to cavitation, and corrosion in conditions of fatigue stress is four times greater than for the bronzes with $\mathrm{Mn}$.

In this article, we present the results of the experiments concerning the mass loss of two types of bronzes in seawater under cavitation, using an experimental setup built by us [7]. The equations of the mass loss in time are determined, and the gravimetric indices are provided for comparing the materials' resistance to corrosion.

\section{Materials and methods}

The studied materials are two bronzes, with the following composition:

- A bronze with $83.09 \% \mathrm{Cu}, 6.4 \% \mathrm{Sn}, 4.40 \%$

$\mathrm{Pb}, 4.07 \% \mathrm{Zn}$, called in the following Bronze 1;

- A bronze with $80.54 \% \mathrm{Cu}, 9.85 \% \mathrm{Al}, 4.59 \%$

$\mathrm{Fe}, 4.40 \% \mathrm{Ni}$, called in the following Bronze 2.

These materials have been chosen because they are used for elements of ships working under pressure and cavitation, as pipes, fittings, joining components, and propellers.

Bronze 1 belongs to the class of the bronzes with $\mathrm{Sn}, \mathrm{Zn}$, and $\mathrm{Pb}$, while Bronze 2 is a bronze with $\mathrm{Al}$ and $\mathrm{Ni}$.

The composition of the seawater used for all the experiments is the following: salinity: $22.17 \mathrm{~g} / \mathrm{L}$ $\mathrm{NaCl}, 0.31 \mathrm{~g} / \mathrm{L}, \mathrm{pH}=7,6.27 \mathrm{meq} / \mathrm{L}$ - total water hardness, $0.051 \mathrm{mg} / \mathrm{L} \mathrm{Fe}, 0.0033 \mathrm{mg} / \mathrm{L} \mathrm{Ni}$.

The experimental setup used for studying the mass loss in the cavitation field is presented in Fig.1 [7-10]. It is mainly formed by the tank where the studied liquid is introduced (1); the high frequency $(20 \mathrm{~Hz})$ generator (8); a ceramic transducer (7) that is excited by the generator; a pair of copper electrodes (13), with the role of collecting the electrical signals produced during the periods when the generator works; a cooling fan (11) utilized for preserving a constant temperature (in this case $20^{\circ} \mathrm{C}$ ) of the liquid during the experiment (given that the cavitation is an exogenous process); the command block (12) used for selecting different powers for the generator regime $(80 \mathrm{~W}, 120 \mathrm{~W}$, or $180 \mathrm{~W})$.

The samples were kept in saline water under cavitation produced by ultrasound for a total of 1320 
minutes $(380$ minutes at $80 \mathrm{~W}, 480$ minutes at $120 \mathrm{~W}, \quad$ and weighted every 20 minutes. and 480 minutes at $180 \mathrm{~W}$ of the generator power)

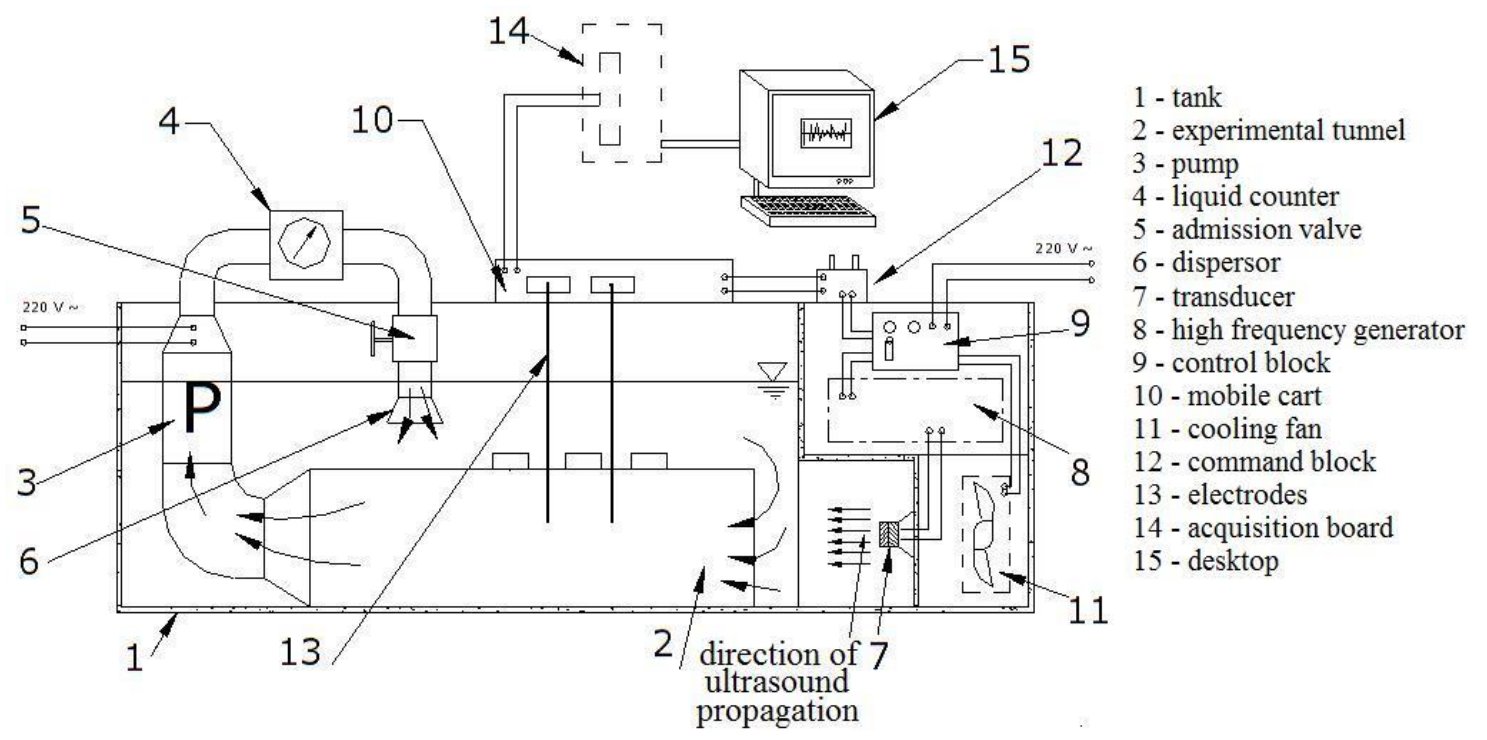

Fig. 1. The experimental setup

The mass loss trend of each material at each power level has been determined and validated by statistical methods. The determination coefficients $\left(\mathrm{R}^{2}\right)$ and the residuals' standard deviation (s) are reported. An $\mathrm{R}^{2}$ close to 1 and a residual standard deviation close to zero indicate a good fit.

The Kolmogorov-Smirnov, the portmanteau, and the Levene tests [11] have been performed for testing that the residual forms a Gaussian white noise. The tests have been performed at a significance level of $5 \%$.

To determine if the mass loss series at the threepower level come from the same distribution, the Kruskal-Wallis test [12] has been performed. If the null hypothesis was rejected, the non-parametric Wilconxon test [13] has been performed to test the same hypothesis for pairs of series.

To quantitatively appreciate the corrosionerosion, the absolute mass variation on the surface (S) and the gravimetric indexes (mass loss in time and per surface) have been determined.

\section{Results and discussion}

Let us denote by:

- $t$ - the time,

- $\quad m_{t}$ - the sample mass at the moment $\mathrm{t}$,

- $R^{2}$ - the determination coefficient,

- $\quad s$ - the residual standard deviation,

- $\quad S$ - the total surface of a sample.

Figures 2 (a)-(c) (Figure 3 (a)-(c)) show the mass evolution of the sample of Bronze 1 (Bronze 2) at each power level of the generator. Figure 2 (d) (Figure 3 (d)) shows the overall evolution of the mass of the same sample.

For Bronze 1, the equations of the mass variation are polynomial of the second degree, when the generator worked at $80 \mathrm{~W}$ and $120 \mathrm{~W}$, while when working at $180 \mathrm{~W}$ is, the polynomial is of the third order. In all cases, $\mathrm{R}^{2}$ (Fig. 2 (a)-(c)) is above 0.92, and the residual standard deviations are lower than 0.0002 , indicating a good fit of the recorded values. Residuals' analysis shows all the residuals in the models form a white noise.

Kruskal - Wallis and the Wilconxon tests rejected the null hypotheses, so one cannot find enough evidence that there is no difference between the time series. Hence, the corrosion trend depends on the generator's power.

For Bronze 2, the mass loss is described by third-degree polynomials at $80 \mathrm{~W}$ and $180 \mathrm{~W}$ and a second-degree polynomial at $120 \mathrm{~W}$. The corresponding $\mathrm{R}^{2}$ are higher for Bronze 2 than for Bronze 1, with the residuals standard deviations less than 0.00007. The residuals in the models form white noises. Again, the null hypotheses have been rejected by Kruskal - Wallis and the Wilconxon tests, confirming that the generator's power influences the mass loss.

The studied samples mass variation during the experiments is:

- for Bronze 1: 


$$
m_{t}=17.244908-5.075136 \cdot 10^{-6} t+1.887143 \cdot 10^{-10} t^{2}
$$

with a standard deviation $\mathrm{s} s=0.00019783$ and $\mathrm{R}^{2}=$ 0.9911;

- for Bronze 2:

$$
m_{t}=23.445849-8.922002 \cdot 10^{-6} t+2.798266 \cdot 10^{-10} t^{2}
$$

with $s=0.000228$ and $\mathrm{R}^{2}=0.9904$.

To determine the material with the best behavior in cavitation conditions, the absolute mass variation per surface [in $\mathrm{g} / \mathrm{m}^{2}$ ] has been computed, using the formula:

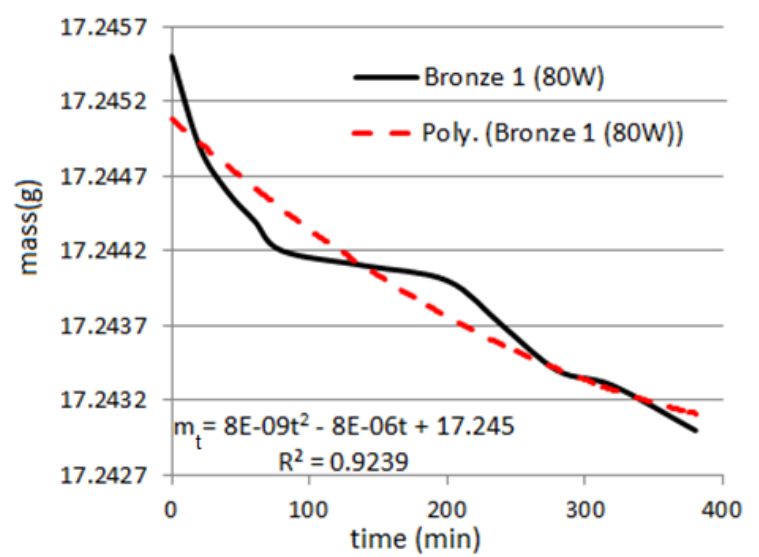

(a)

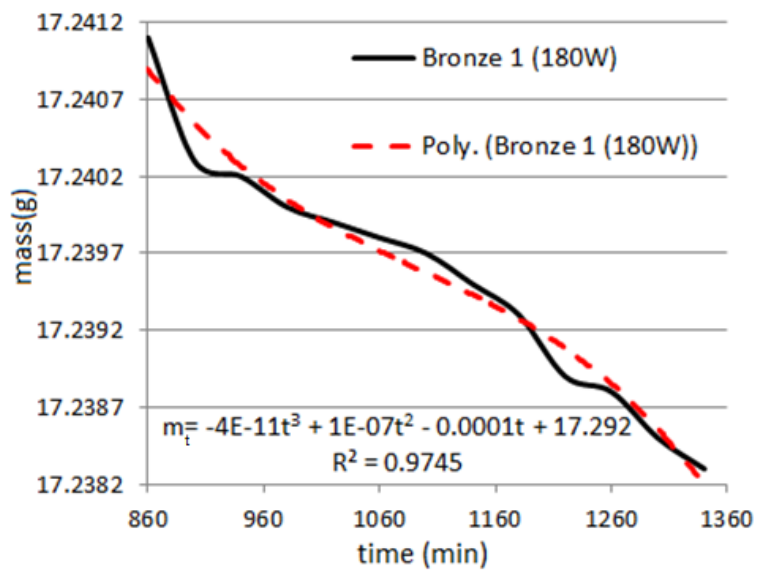

(c)

$$
\Delta m_{t} / S=\left(m_{1}-m_{t}\right) / S
$$

where $S$ is the surface of the sample, $m_{1}$ is the sample mass at the beginning of the experiment, and $m_{t}$ is the mass of the sample at the moment $t$.

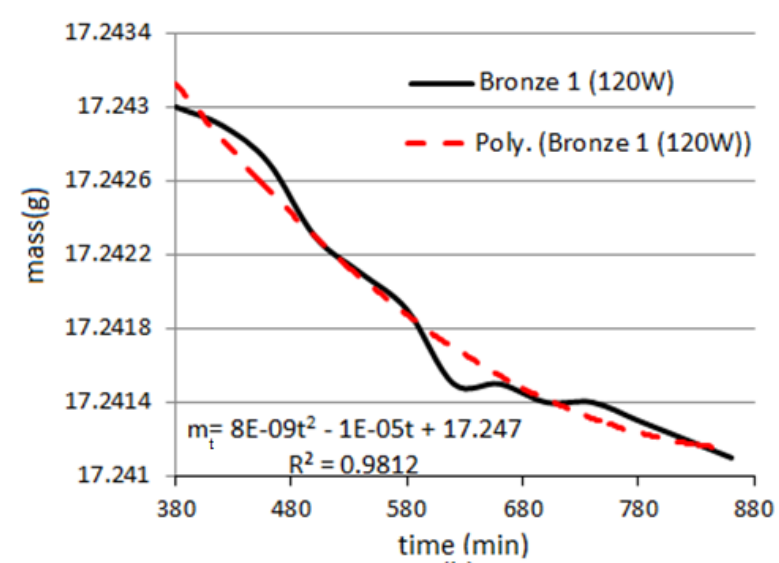

(b)

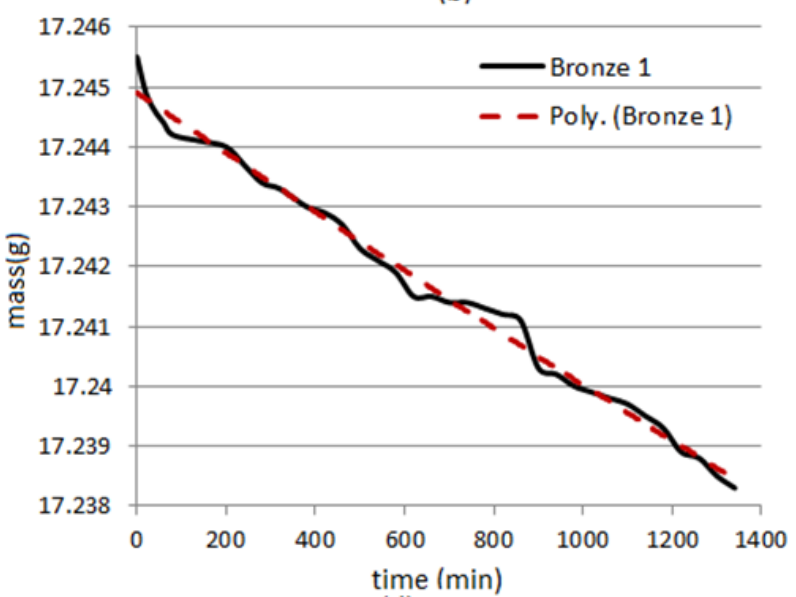

(d)

Fig. 2. The mass variation of Bronze 1: (a) at $80 \mathrm{~W},($ b) at $120 \mathrm{~W}$, (c) at $180 \mathrm{~W}$, (d) during the entire experiment. The continuous line represents the recorded data, and the dotted ones the fitted trend

The charts of mass variation per surface for both materials are presented in Fig. 4. The continuous curves represent the data series, whereas the dotted ones are the fitted trends. Remark that Bronze 2 experiences the highest values compared to Bronze 2, significantly higher at the third power level. All the models fitted for the series trends have $\mathrm{R}^{2}$ greater than 0.97 .
The trend equations for the total variation of the mass in time per surface are respectively:

- for Bronze 1:

$$
\Delta m_{t} / S=0.0758+0.1237 t-0.0003 t^{2},(4)
$$


with $s=0.11308$ and $\mathrm{R}^{2}=0.9933$, and

- for Bronze 2:

$$
\Delta m_{t} / S=0.1609+0.1513 t-0.0019 t^{2},
$$

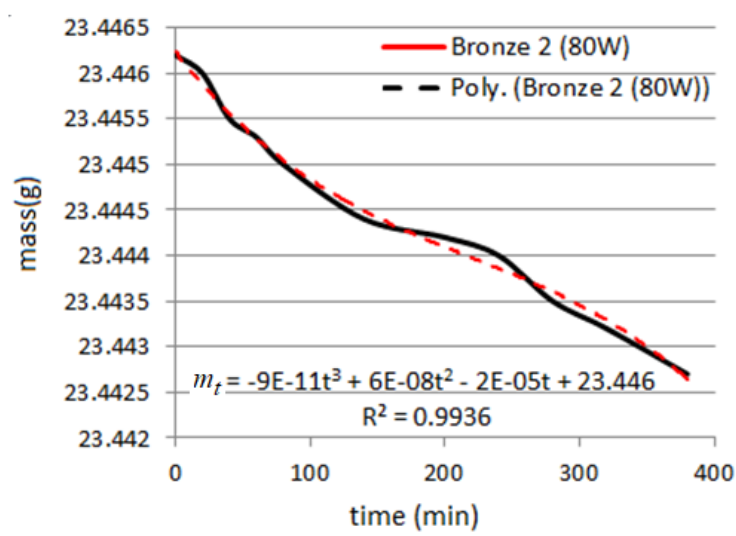

(a)

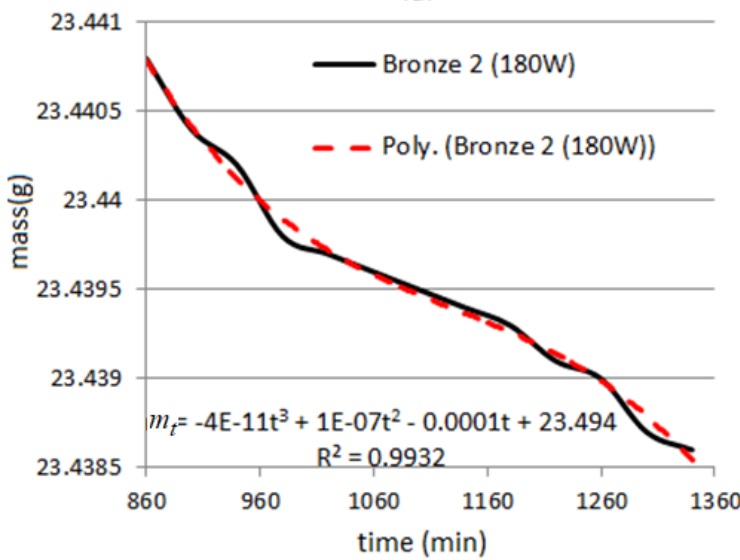

(c) with: $s=0.0894$ and $\mathrm{R}^{2}=0.9908$.

Finally, the gravimetric indices have been computed in all scenarios, based on the data from Fig. 4. They are presented in Table 1.

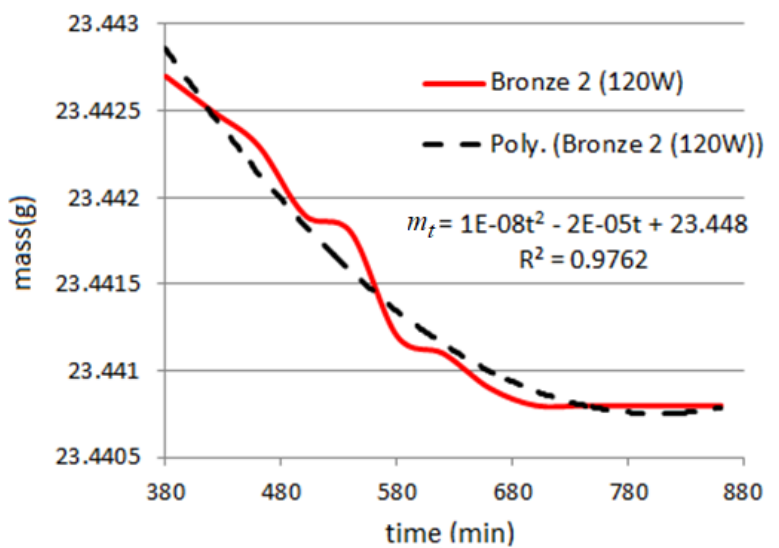

(b)

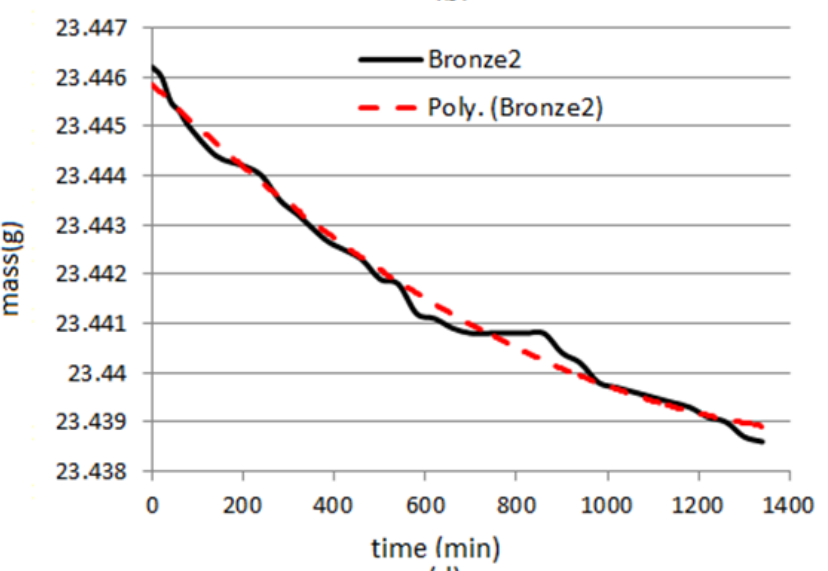

(d)

Fig. 3. The mass variation of Bronze 2: (a) at $80 \mathrm{~W}$, (b) at $120 \mathrm{~W}$, (c) at $180 \mathrm{~W}$, (d) during the entire experiment. The continuous line represents the recorded data, and the dotted ones, the fitted trend

Table 1. The gravimetric indices $\left[\mathrm{g} / \mathrm{m}^{2} \mathrm{~h}\right]$

\begin{tabular}{|c|c|c||}
\hline Power [W] & Bronze 1 & Bronze 2 \\
\hline 80 & 0.2256 & 0.2166 \\
\hline 120 & 0.1357 & 0.0931 \\
\hline 180 & 0.2000 & 0.1078 \\
\hline
\end{tabular}

The highest gravimetric index is that of Bronze 1 , in the first scenario, while the lowest is that of Bronze 2, at $120 \mathrm{~W}$. Unexpectedly, the highest gravimetric index was obtained at $80 \mathrm{~W}$ for both bronzes and the lowest for the second one. 


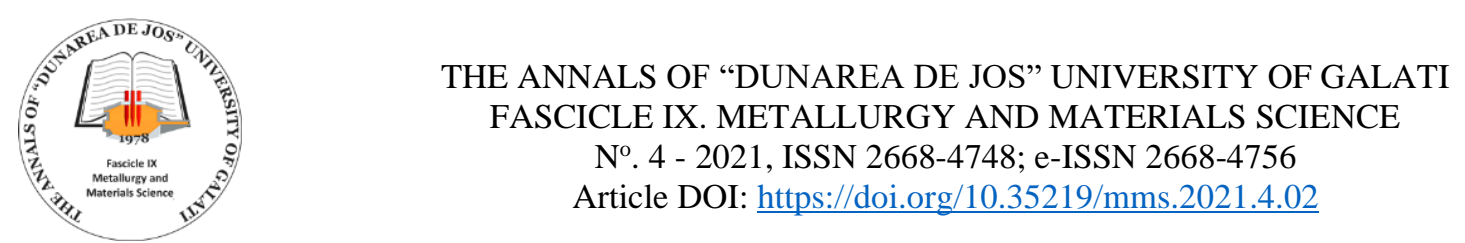

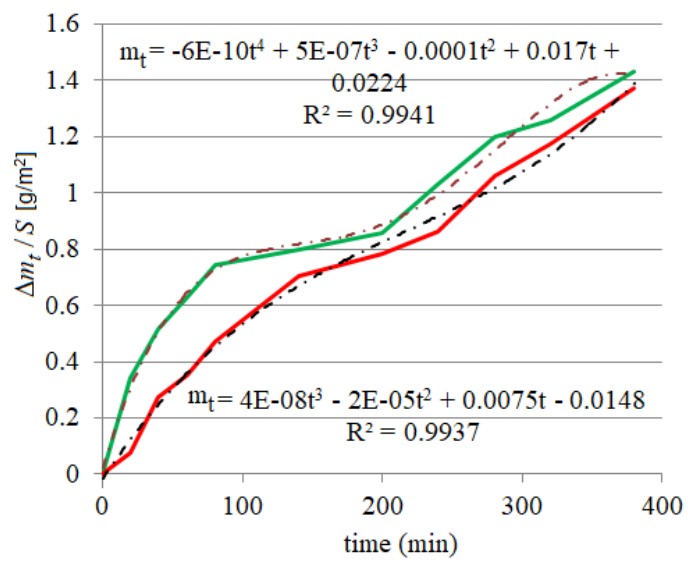

(a)

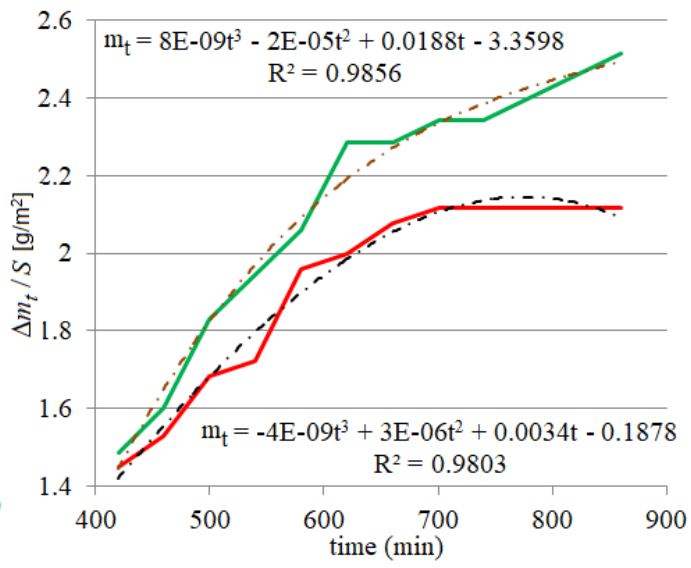

(b)

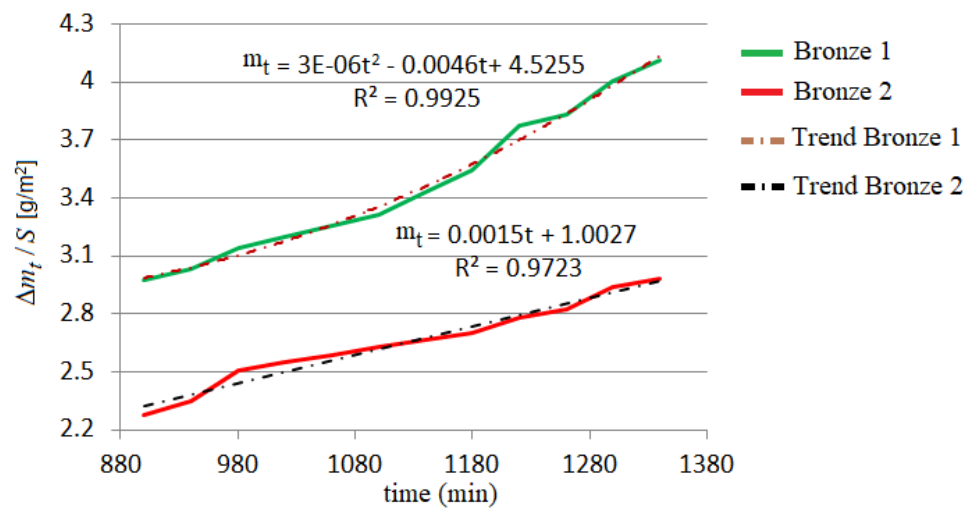

(c)

Fig. 4. The variations in time of absolute mass per surface at: (a) $80 \mathrm{~W}$, (b) $120 \mathrm{~W}$ and (c) $180 \mathrm{~W}$

\section{Conclusion}

The experiments of mass loss in ultrasound cavitation field proved that bronze with $\mathrm{Sn}$ has a lower resistance than that with Al. The gravimetric indices show the highest mass loss at the first stage of the generator. The study show that the corrosion speed is higher than in freshwater [10] due to the accentuated chemical corrosion that appears due to the salt content.

For future, it would be interesting to study the mass loss of the same materials in circulating liquids given the importance of these materials for the naval constructions.

\section{References}

[1]. Schüssler A., Exner H. E., The corrosion of nickel-aluminium bronzes in seawater - I. Protective layer formation and the passivation mechanism, Corros. Sci., 3(11), p. 1793-1802, 1993. [2]. Wharton J. A., et al., The corrosion of nickel-aluminium bronze in seawater, Corros. Sci., 47(12), p. 3336-3367, 2005. [3]. Basumatary J., Nie M., Wood J. K., The synergistic effects of cavitation erosion-corrosion in ship propeller materials, J. BioTribo-corros., 1, p. 1-12, 2015.
[4]. Wharton J. A., Stokes K. R., The influence of nickelaluminium bronze microstructure and crevice solution on the initiation of crevice corrosion, Electrochim. Acta, 53 (5), p. 24632473, 2008.

[5]. Basumatary J., Wood R. J. K., Synergistic effects of cavitation erosion and corrosion for nickel aluminium bronze with oxide film in 3.5\% NaCl solution, Wear, 376-377, p. 1286-1297, 2017.

[6]. Ivanov I. V., Corrosion resistant materials in food industry, Editura Agro-Silvica Bucuresti, Romania, 1959.

[7]. Bărbulescu A., Marza V., Dumitriu C. S., Patent no RO 123086-B1 (30.09.2010) Installation and method for measuring and determining the effects produced by cavitation in ultrasound field in stationary and circulating media, 2010.

[8]. Bărbulescu A., Models of the voltage induced by cavitation in hydrocarbons, Acta Phys. Pol. B, vol. 37 (10), p. 2919-2931, 2006. [9]. Bărbulescu A., Dumitriu C. S., Mathematical aspects of the study of the cavitation in liquids, in Mathematical Modelling of Environmental and Life Sciences, S. Ion, G. Marinoschi and C. Popa, Eds. București: Editura Academiei Române, p. 7-14, 2006.

[10]. Dumitriu C. S., Bărbulescu A., Studies about the copper base alloys used in naval constructions - modeling the loss mass in different media, Sitech, Craiova, 2007.

[11]. Bărbulescu A., Studies on time series. Applications in Environmental Sciences, Springer, 2016.

[12]. Kruskal W. H., Wallis W. A., Use of ranks in one-criterion variance analysis, J. Am. Stat. Assoc., vol. 47 (260), p. 583-621, 1952.

[13]. Mann H. B., Whitney D. R., On a Test of Whether one of Two Random Variables is Stochastically Larger than the Other, Ann. Math. Stat., 18 (1), p. 50-60, 1947. 